\title{
Lipid-lowering, cardiovascular and anti-inflammatory effects of «Letium» in patients with hypertension
}

Prof. Kochueva M.N., prof. Korzh A.N., PHD Kochuev G.I., ass. Gavriluk V.A., ass. Plehova O.A*.

Kharkiv Medical Academy of Postgraduate Education, * Kharkiv National Medical University

This paper studied the dynamics of the lipid spectrum of blood and functional state of the endothelium of blood C-reactiveprotein (CRP) in patients with hyper tensionstage 1-2, which were additional factors of cardiovascular risk, under the influence of adjuvant the rapy with the use of the drug Letium. 12-week ther a py with the inclusionof Letiuma was a ccompaniedby a statistical lysignifican treduction in plasma total cholesterol, total TG, LDL cholesterol, a the rogenic factor an dincreased levels of antia the rogenic HDL cholesterol.

Key Words: hypertension, C-reactiveprotein, lipid lowering the rapy, endo the liumvasodilatation.

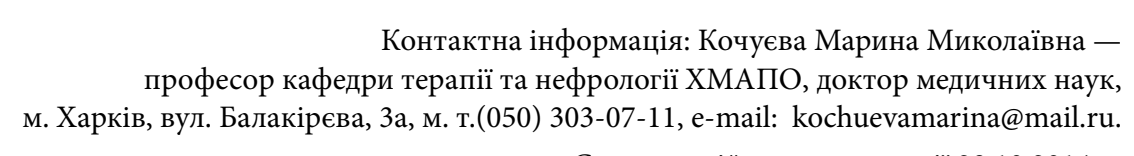

Стаття надійшла до редакції 28.10.2014 p.

\section{НА ДОПОМОГУ ЛІКАРЮ}

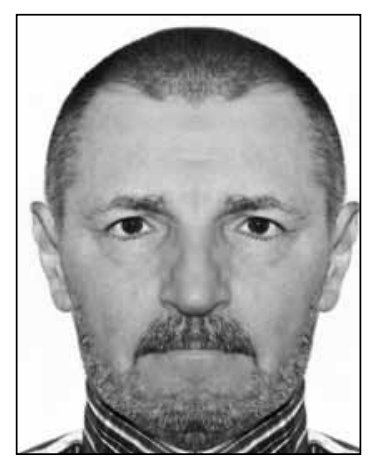

\author{
Доц. С.В. Краснокутский
}

Харьковская медицинская академия последипломного образования

Кафедра общей практики-семейной медицины

\section{КАинический разбор пациента с болью в груАной кметке}

22.01.2009 г. Пациент Р., 54 лет, обратился на консультацию с жалобами на боли за грудиной жгущего и ноюшего характера, возникающие 1-3 раза в сутки, как правило, по утрам во время ходьбы от дома на автобусную остановку. Боли появились около 3-х месяцев назад. Причину боли объясняет изжогой, поэтому при возникновении боли пациент принимает 1 пакетик суспензии Маалокса (антацид), через 1-2 мин боль проходит.

В анамнезе - язвенная болезнь 12-перстной кишки, артериальная гипертензия. Курит по 0,5-1 пачке сигарет в день в течение 25 лет.

Через неделю после возникновения болей за грудиной обратился в поликлинику, где было диагностировано обострение язвенной болезни 12-перстной кишки, назначены фамотидин по 20 мг 2 раза в день и де-нол по 1 таблетке 4 раза в день. Также были сделаны клинические анализы крови и мочи (без патологии) и ЭКГ. На ЭКГ врач заподозрила инфаркт миокарда, в связи с чем проведен тропониновый тест. Тест дал отри- иательный результат, жалоб пациент не предьявлял и от дальнейших консультаций отказался.

На фоне назначенного лечения состояние не улучшилось - приступь боли за грудиной не прекратились.

Какова дальнейшая тактика врача?

Каковы возможные причины боли в области сердца и за грудиной?

Причины боли в области сердца и за грудиной: - Стенокардия

- Некоронарогенные кардиалгии

Основные заболевания некоронарной природы, сопровождающиеся болями в области сердца, можно сгруппировать следующим образом:

1) заболевания периферической нервной системы: шейно-плечевые радикулиты различной природы, симпаталгии, межреберная невралгия, шейноплечевой плексит, раздражение нервных сплетений и стволов зоны C5-D6; 
2) патология ребер;

3) группа заболеваний желудочно-кишечного тракта, которые вызывают либо смещение сердца, либо по локализации болей могут имитировать стенокардию;

4) заболевания легких, плевры, средостения;

5) воспалительные заболевания сердца;

6) синдром передней грудной стенки.

В отличие от стенокардии боли при некоронарогенной кардиалгии отличаются тем, что не связаны непосредственно с физической нагрузкой, продолжаются дольше (не прекращаются практически сразу после прекращения нагрузки), как правило, пациент может указать точку, в которой болит (и там может быть болезненность при пальпации). Боль по характеру - часто колющая, усиливается при наклонах и поворотах туловища.

\section{Прежде всего нужно исключить стенокардию} напряжения

При стенокардии напряжения боль не бывает продолжительной. Она длится несколько минут, заканчивается обычно сразу с прекращением физического напряжения, спровоцировавшего боль, или через $1-2$ минуты после приема нитратов. Боль полностью исчезает под влиянием нитратов. Если же боль, возникшая при физическом напряжении или эмоции, продолжается свыше 30 мин, то, по-видимому, дело касается не простого приступа стенокардии, но, возможно, инфаркта миокарда. Если боль сопровождается холодным потом и падением артериального давления или обмороком, это подозрительно в отношении инфаркта миокарда.

Никакими объективными сведениями подтвердить стенокардию вне приступа нельзя. Если на высоте боли удается снять электрокардиограмму, то в некоторых случаях можно зарегистрировать смещение сегмента ST и изменение зубца Т. Характер этих смещений определяется локализацией очага ишемии. Важно повторно снимать электрокардиограмму в течение 3-4 дней после приступа.

Стенокардия напряжения может наблюдаться также при сифилитическом мезаортите, она является типичным признаком аортального стеноза. Распознавание этих заболеваний обычно не является сложным, если помнить, что стенокардия - лишь один и неспецифический симптом среди других признаков, определяющих диагноз в одном случае сифилиса аорты, в другом - сужения аортального устья.

Мы предположили, что причина приступов боли за грудиной - стенокардия напряжения. Приступы возникали утром во время ходьбы и прекращались не из-за приема антацида, а просто вследствие прекращения физической нагрузки (пациент, для того, чтобы выпить суспензию Маалокса, останавливался)
Объективно. Пациент повышенного питания. Кожа - обычного цвета. В легких - редкие сухие рассеянные хрипы на вдохе и на выдохе, выдох не удлинен. ЧД - 13 в 1 мин. ЧСС - 78. АД - 150/100. Сердечный ритм правильный. Шумов нет. Живот мягкий, болезненный в эпигастрии. Печень не увеличена. Отеков нет.

На ЭКГ (приведены только грудные отведения) ритм синусовый, дыхательная аритмия, вероятно гипертрофия левого желудочка 2 степени. В целом ЭКГ - без существенных изменений, за исключением элевации сегмента ST в отведениях V3-V6 (см. ниже).

Какие вероятные причины элевации сегмента ST?

1) Инфаркт миокарда

2) Перикардит

3) Синдром ранней реполяризации

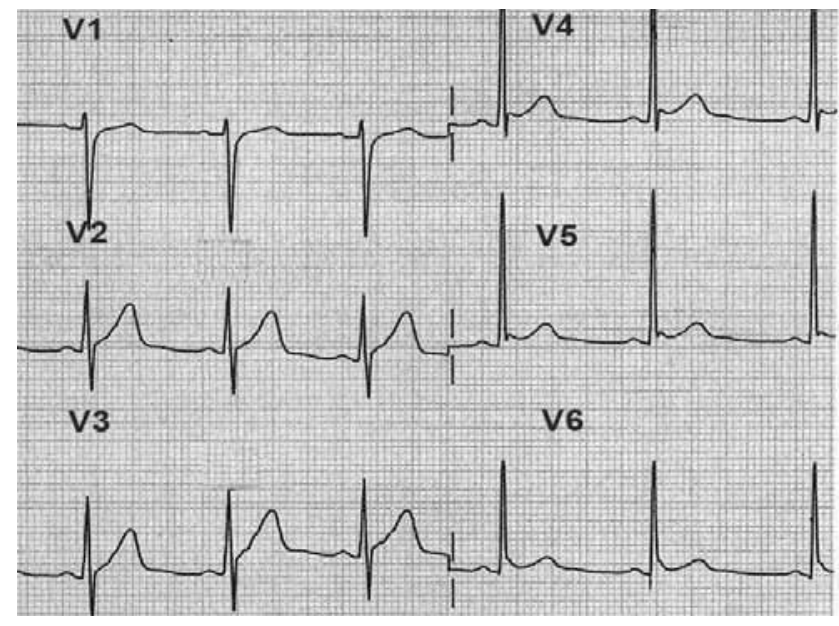

Синдром ранней реполяризации желудочков (РРЖ) встречается как у здоровых, так и у больных с различными заболеваниями сердца. В большинстве случаев синдром РРЖ выявляется в левых грудных отведениях $\left(\mathrm{V}_{4}-\mathrm{V}_{6}\right)$. Основные признаки:

1) подәем сегмента $R S-T$ выше изолинии с выпуклостью, обращенной книзу;

2) высокое расположение на нисходящем колене зубца $R$ точки соединения (J), иногда представленной в виде зазубрины, или псевдозубиа $S$;

3) уменьиение или исчезновение зубиа $S$ в левых грудных отведениях

Инфаркт миокарда (ИМ) был исключен по 2-м причинам: отсутствие клиники и нетипичные для ИМ изменения процессов реполяризации. Для успешной дифференциальной диагностики «инфарктной» элевации ST необходимо отличать первичные и вторичные нарушения процессов реполяризации. Первичные нарушения - это признак поражения миокарда (ИМ, очаговый миокардит), вторичные - следствие нарушения внутрижелудочковой проводимости (в/ж блокады, синдром WPW, гипертрофия миокарда ЛЖ 3-й степени). 
Отличия первичных и вторичных нарушений реполяризации

\begin{tabular}{|c|c|c|}
\hline Признаки & $\begin{array}{c}\text { Первичные нару- } \\
\text { шения }\end{array}$ & $\begin{array}{c}\text { Вторичные наруше- } \\
\text { ния }\end{array}$ \\
\hline QRS & Не уширен & $\begin{array}{c}\text { Увеличен в ширину } \\
\text { или по амплитуде }\end{array}$ \\
\hline $\begin{array}{c}\text { Направление } \\
\text { смещения ST }\end{array}$ & Не имеет значения & $\begin{array}{c}\text { Противоположно } \\
\text { основному зубцу QRS }\end{array}$ \\
\hline Форма ST & $\begin{array}{c}\text { Выпуклость в сто- } \\
\text { рону смещения или } \\
\text { горизонтальный }\end{array}$ & $\begin{array}{c}\text { Выпуклость противо- } \\
\text { положно направлению } \\
\text { смещения }\end{array}$ \\
\hline $\begin{array}{c}\text { Направление } \\
\text { зубца T }\end{array}$ & $\begin{array}{c}\text { Чаще отрицатель- } \\
\text { ный }\end{array}$ & $\begin{array}{c}\text { В сторону смещения } \\
\text { ST }\end{array}$ \\
\hline Форма T & $\begin{array}{c}\text { Равностороннй, } \\
\text { заострен }\end{array}$ & $\begin{array}{c}\text { Начальная ветвь } \\
\text { более пологая, за- } \\
\text { круглен }\end{array}$ \\
\hline
\end{tabular}

Перикардит также был исключен - учитывая отсутствие патологических изменений в клиническом анализе крови и отсутствие признаков перикардита на эхокардиографии. Также проведены: УЗИ внутренних органов, допплерография почечных и сонных артерий (патологии не выявлено).

Проведены биохимические исследования:

1) липидограмма (выявлена дислипидемия)

2) исследование электролитов (для исключения вторичной гипертензии, патологии не выявлено).
Таким образом, причина элевации сегмента ST - синдром ранней реполяризации. Именно по причине элевации ST врач поликлиники и заподозрил у пациента ИМ.

Какими методами можно верифицировать диагноз «стабильная стенокардия»?

1) нагрузочные пробы (велоэргометрия, тредмил)

2) суточное ЭКГ-мониторирование

3) коронарография

От коронарографии пациент отказался, было назначено суточное ЭКГ-мониторирование.

Пациенту было рекомендовано лечение:

1) изосорбид-5-мононитрата 40 мг (ретардная форма) 1 раз в сутки в 7:00 утра

2) аспирин 100 мг ежедневно

3) аторвастатин 10 мг 1 раз

4) нитроглицерин 1 таблетке под язык во время приступа боли за грудиной

5) гипокалорийная диета

6) прекращение курения

Через 2 дня после назначения терапии было проведено суточное мониторирование. Эпизодов депрессии ST не выявлено.

Боли за грудиной прекратились.

Матеріал надійшов до редакції 29.10.2014 р.

\section{ПИТАННЯ ФІЗІОТЕРАПІЇ}

УДК 612.01:616-036.82

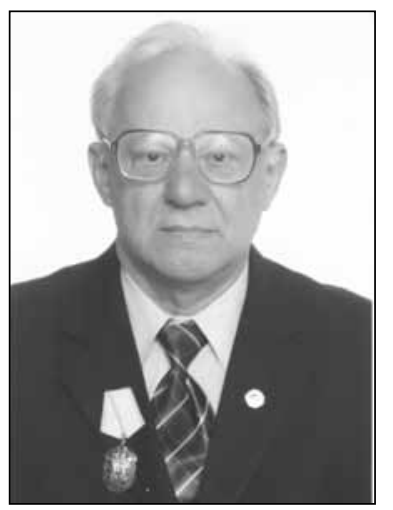

Проф. Л.Д. Тондий

Харьковская медицинская академия последипломного образования

Кафедра курортологии и физиотерапии

\section{О самозащите организма и возможностях ее укрепмять (как родимась новая меАицинская наука)}

$\mathbf{Q}$ истории человечества немало плохих страниц. ВЭто - войны, катаклизмы природного характера, пандемии, эпидемии, которые охватывали целые континенты, страны, города и селенья. От чумы, холеры, тифов и других инфекционных заболеваний вымирало большое количество людей. Но какая - то часть выживала, несмотря на отсутствие эффективных лекарств, нарушение всех правил санитарии и гигиены.
Почему выживали?

Другой пример, уже из нашей действительности. Почти каждый год нас посещает эпидемия или вспышка гриппа, острых респираторных заболеваний. Армия врачей вступает в борьбу с этими коварными и очень заразными заболеваниями. Но врачи по-разному реагируют на контакты с болезнью. Одни после посещения первого же больного заболевают и тяжело переносят эту инфекцию, а другие на про- 